\title{
ChemComm
}

\section{Sulfonyl chlorides as an efficient tool for the postsynthetic modification of $\mathrm{Cr}-\mathrm{MIL}-101-\mathrm{SO}_{3} \mathrm{H}$ and $\mathrm{CAU}-1-\mathrm{NH}_{2} \dagger$}

Cite this: Chem. Commun., 2014 50, 9306

Received 16th May 2014,

Accepted 21st June 2014

DOI: $10.1039 / c 4 c c 03746 d$

www.rsc.org/chemcomm

\author{
Arne Klinkebiel, ${ }^{a}$ Nele Reimer, ${ }^{\mathrm{b}}$ Martin Lammert, ${ }^{\mathrm{b}}$ Norbert Stock $^{\mathrm{b}}$ and \\ Ulrich Lüning ${ }^{\star a}$
}

\begin{abstract}
Postsynthetic modification can be used to introduce sulfonamide functionalities into MOF frameworks. Using sulfonyl chlorides as reactive intermediates, $\mathrm{Cr}-\mathrm{MIL}-\mathrm{SO}_{3} \mathrm{H}$ and $\mathrm{CAU}-1-\mathrm{NH}_{2}$ have been further modified to give hitherto unknown functionalized MOFs in which a sulfonamide group is bound to the framework either by its $\mathrm{N}$ or its $\mathrm{S}$ atom.
\end{abstract}

Among the classes of porous materials, metal-organic frameworks (MOFs) or porous coordination polymers (PCPs) represent a highly versatile group of compounds. ${ }^{1}$ By varying the nature of the organic linker as well as the coordination environment of the constituting metal ions, these materials offer numerous opportunities to vary physical and chemical properties of the pore surface. They are promising materials for applications such as gas adsorption, separation, catalysis, chemical sensing, drug delivery. ${ }^{2}$ Variation of the functionality of the organic linker molecules can be achieved by postsynthetic modification. ${ }^{3}$ The introduction of already functionalized linkers is limited, due to the possible interference of the functional groups in the formation of the desired framework or their incompatibility with the reaction conditions. Nevertheless, numerous presynthetically modified MOFs have been described (e.g. amino, ${ }^{4}$ hydroxyl,${ }^{5}$ formyl,${ }^{6}$ alkyne ${ }^{7}$ and azide ${ }^{8}$ containing structures). From these functionalized MOFs, postsynthetic modification opens a wide field of different derivatives like amides, ${ }^{4 f, 9}$ imines, $^{10}$ ureas and triazoles. ${ }^{7,8,11}$ To expand the available synthetic opportunities, it is of great importance to develop new synthetic strategies and methods for modifying functional groups which have not been successfully functionalized further until now. For example, the synthesis of frameworks containing non-coordinating acidic groups

\footnotetext{
${ }^{a}$ Otto-Diels-Institut für Organische Chemie, Olshausenstr. 40, 24098 Kiel, Germany. E-mail: luening@oc.uni-kiel.de

${ }^{b}$ Institut für Anorganische Chemie, Max-Eyth-Strasse 2, 24118 Kiel, Germany. E-mail: stock@ac.uni-kiel.de

$\dagger$ Electronic supplementary information (ESI) available: Experimental details, ${ }^{1} \mathrm{H}$-NMR spectroscopy, FT-IR spectroscopy, XRPD data, adsorption isotherms. See DOI: $10.1039 / \mathrm{c} 4 \mathrm{cc} 03746 \mathrm{~d}$
}

is difficult and therefore reports on postsynthetic modifications are rare. ${ }^{12}$

The class of sulfonamides, which is well-known for its antibacterial effects acting as antimetabolites ${ }^{13}$ or their catalytical properties, ${ }^{14}$ can be synthesized from sulfonic acids and amines. The chemical and electronic properties of the sulfonamide group are of great importance. Due to the strong electron-withdrawing effect of the sulfonyl group, the amide proton is acidic. Compared to carbonamides, a sulfonamide is more stable under basic aqueous conditions and the hydrogen-bond strength is enhanced. ${ }^{15}$

Here we show that the class of sulfonamides is accessible by tandem post-modification of the Cr-MIL-101- $\mathrm{SO}_{3} \mathrm{H}$ using the corresponding sulfonyl chloride as a reactive intermediate. Extending our concept by treating an amino-containing network like CAU-1- $\mathrm{NH}_{2}{ }^{4 f}$ with sulfonyl chlorides, it is possible to synthesize MOFs with a reversed orientation of the sulfonamide functionality as well.

The MIL-101 framework which is composed of chromium(III), 2-sulfoterephthalate and 2-sulfonate-terephthalate anions reported by Kitagawa and co-workers ${ }^{16}$ is one of a few existing $\mathrm{MOFs}^{17}$ containing a non-coordinating sulfonic acid. To the best of our knowledge, there has been no postsynthetic modification of this group described until now. We modified it to different $N$-alkyl and $N$-aryl substituted sulfonamides (3a-f) as well as an $N$-pyridine substituted one (3g) (Scheme 1).

PXRD data (ESI $\dagger$ ) demonstrate that all structures are intact after the modification. Infrared spectra of compounds $\mathbf{3 a - g}$ (ESI $\dagger$ ) show characteristic bands for the introduced alkyl and aryl substituents as well as for sulfonamides. The $\mathrm{N}_{2}$ adsorption isotherms (ESI $\dagger$ ) of the functionalized Cr-MIL-101 3a-g samples exhibit the characteristic shape, while the sorption capacity slightly decreases as expected upon postsynthetic modification in comparison to starting material 1. The decrease is only $20 \%$ for the methyl substituted sulfonamide $3 \mathrm{a}$, but $50 \%$ if benzyl substituted (3f). However for comparison of the different MOFs with one another, the varying degrees of post-synthetic modification $(70 \%$ for $3 \mathrm{a}, 50 \%$ for $3 \mathrm{~g})$ have to be taken into consideration. 
<smiles>[R]S(=O)(=O)c1cc(C(=O)OC2CCCCC2)ccc1C(=O)OC1CCCCC1</smiles>

a $\mathrm{R}=-\mathrm{NHMe}(\sim 70 \%)$ e $\mathrm{R}=-\mathrm{NHPh}(\sim 60 \%)$

b $\mathrm{R}=-\mathrm{NHEt}(\sim 65 \%) \quad$ f $\mathrm{R}=-\mathrm{NHBn}(\sim 50 \%)$

c $\mathrm{R}=-\mathrm{NHPr}(\sim 65 \%) \quad \mathrm{gR}=-\mathrm{NHPy}(\sim 45 \%)$

d $\mathrm{R}=-\mathrm{NMe}_{2}(\sim 60 \%)$

Scheme 1 Two-step postsynthetic modification of $\mathrm{Cr}-\mathrm{MIL}-101-\mathrm{SO}_{3} \mathrm{H}$ (1) via sulfonyl chloride $\mathbf{2}$ to produce sulfonamides $3 \mathbf{a}-\mathbf{g}$. (a) Oxalyl chloride, cat. DMF, THF, $24 \mathrm{~h}$, room temp. (b) Corresponding amine, THF, $24 \mathrm{~h}$, room temp.

For further analysis, the MOFs were dissolved in sodium hydroxide, the insoluble chromium salts were removed, and the remaining solution was analyzed by ${ }^{1} \mathrm{H}-\mathrm{NMR}$ data (ESI $\dagger$ ). In Fig. 1, spectra for compound 3a are shown as examples. They exhibit the aromatic signals for the desired sulfonamide 3a and the corresponding unfunctionalized sulfoterephthalic acid of the starting material $\mathbf{1}$. The ratio of the relative integrals allows us to determine the conversion, which is about $70 \%$ (Fig. 1(B)). Due to its water solubility, removal of the linker of starting material 1 (Fig. 1(A)) is possible by extracting the functionalized amide of $\mathbf{3 a}$ with an organic solvent from an acidic solution, whereas the starting material stays mostly in the aqueous phase.
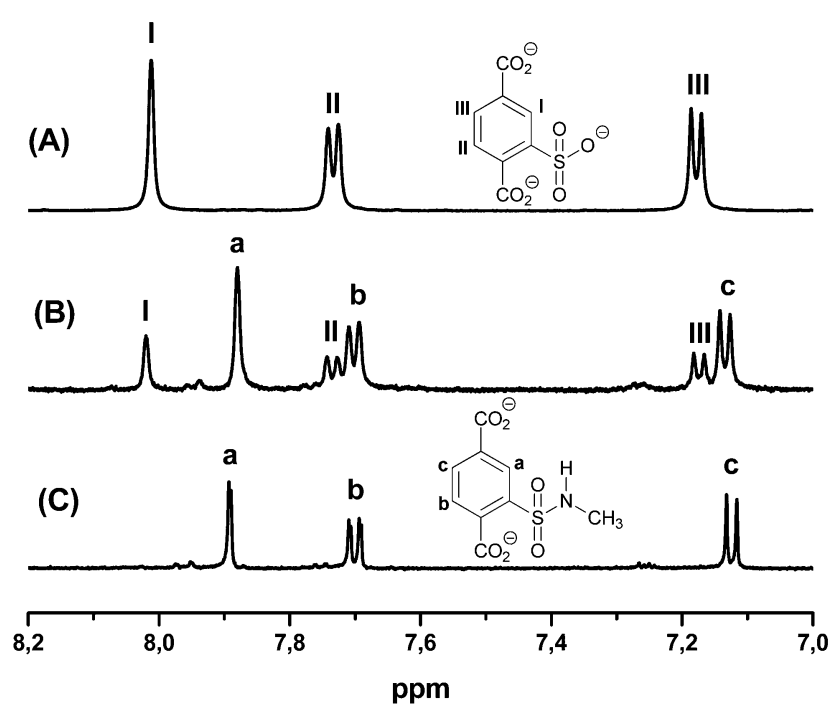

Fig. $1{ }^{1} \mathrm{H}-\mathrm{NMR}$ spectra after dissolving the respective MOF in $\mathrm{NaOD}$ (aliphatic signals are not shown, see ESI† for details): (A) aromatic protons (I-III) of the unfunctionalized linker of starting material 1, (B) mixture of functionalized amide $3 \mathrm{a}(\mathrm{a}-\mathrm{c})$ and unfunctionalized linker (I-III) after postsynthetic modification, $(C)$ terephthalic protons $(a-c)$ of the functionalized amide $3 \mathbf{a}$ after extraction of the unfunctionalized linker.

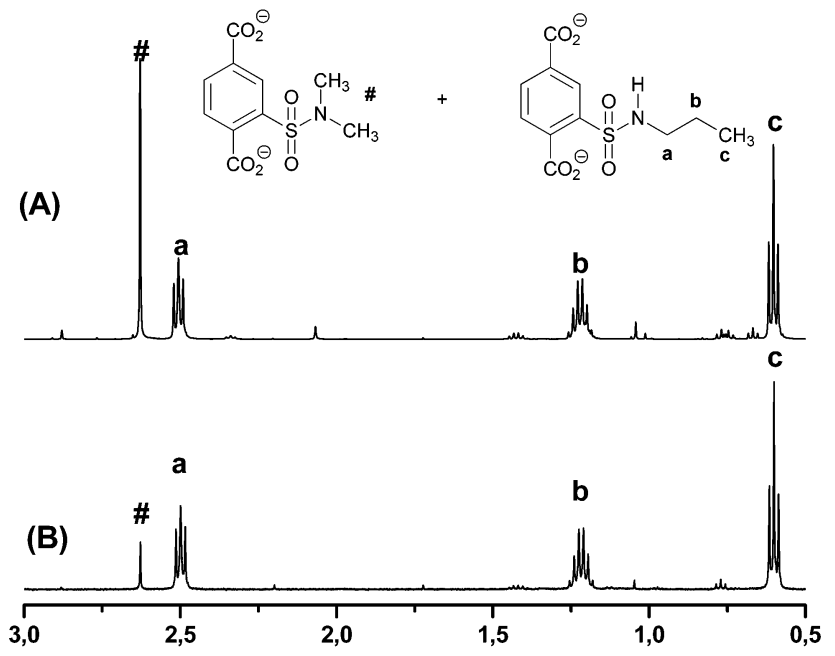

Fig. $2{ }^{1} \mathrm{H}-\mathrm{NMR}$ spectra of the respective MOF in NaOD (aromatic signals are not shown, see $\mathrm{ESI} \dagger$ for details): $N$-propyl sulfonamide $3 \mathrm{c}(\mathrm{a}-\mathrm{c})$ and side product $N, N$-dimethyl sulfonamide $\mathbf{3 d}$ (\#) after using (A) $15 \mu \mathrm{L}$ and (B) $5 \mu \mathrm{L}$ DMF as catalyst.

Comparison of conversion degrees (Scheme 1) shows a dependency on size of the introduced amine and an upper limit of about $70 \%$. Addition of pyridine or triethylamine to scavenge the generated hydrochloric acid showed no improvement of conversion. Due to the instability of the sulfonyl chloride, the reaction temperature was not increased above $25{ }^{\circ} \mathrm{C}$. The upper limit of conversion matches with the conclusion of Kitagawa ${ }^{16}$ for one of three sulfonic acid groups to be deprotonated. The resulting charges are compensating the positive charges of the framework.

In all cases, dimethylsulfonamide $\mathbf{3 d}$ is formed as a byproduct, which results from the reaction of sulfonyl chloride 2 and dimethylamine, which is formed as a sideproduct from the catalytical amount of dimethylformamide added during the reaction. For verification, we synthesized $N, N$-dimethylsulfonamide $\mathbf{3 d}$ as reference. Variation of the catalytical amount of dimethylformamide from $15 \mu \mathrm{L}$ to $5 \mu \mathrm{L}$ showed a significant decrease of this sideproduct, which is shown exemplarily for sulfonamide 3c in Fig. 2. The amount of sideproduct formed varies between 1-5\% (see ESI $\dagger$ for details).

To extend our modification concept of using sulfonyl chlorides as intermediates, it was our next goal to invert the binding sequence of the sulfonamide by treating the amino containing framework CAU-1- $\mathrm{NH}_{2}{ }^{4 f}(5)$ with sulfonyl chlorides in order to obtain related amides 4 and 6 (Scheme 2). The synthesis of sulfonamide 6 was carried out at room temperature due to the instability of 2-pyridinylsulfonyl chloride (ESI $\dagger$ ), which was synthesized according to a literature procedure. ${ }^{18}$ To obtain an $\mathrm{N}$-alkyl substituted sulfonamide, we treated compound $\mathbf{5}$ with methyl sulfonyl chloride, which can withstand higher temperatures (see Table 1).

The ratio of the relative integrals of the desired sulfonamides and the corresponding amino terephthalic acid $\mathbf{5}$ in the ${ }^{1} \mathrm{H}$-NMR spectra of the dissolved material (ESI $\dagger$ ) allows an 
<smiles>CS(=O)(=O)Nc1cc(C(=O)O[AlH2])ccc1C(=O)O[AlH2]</smiles><smiles>Nc1cc(C(=O)OCl)ccc1C(=O)OCl</smiles>

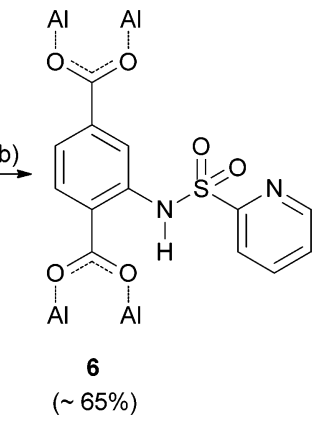

Scheme 2 Postsynthetic modification of $\mathrm{CAU}-1-\mathrm{NH}_{2}$ (5) using methyl and 2-pyridinylsulfonyl chloride giving the sulfonamides 4 and $\mathbf{6}$. (a) For different reaction conditions see Table 1. (b) 2-Pyridinylsulfonyl chloride, pyridine, dichloromethane, $24 \mathrm{~h}$, room temp.

Table 1 Optimization of the reaction conditions for the synthesis of sulfonamide 4: $15 \mathrm{mg} \mathrm{CAU}-1-\mathrm{NH}_{2}, 100 \mu \mathrm{L}$ pyridine (if used), $2.0 \mathrm{~mL}$ methyl sulfonyl chloride ( $\mathrm{mw}=$ microwave)

\begin{tabular}{llll}
\hline Catalyst & Temperature & Reaction time & Conversion (\%) \\
\hline- & $60{ }^{\circ} \mathrm{C}$ & $4 \mathrm{~d}$ & 59 \\
Pyridine & $60{ }^{\circ} \mathrm{C}$ & $24 \mathrm{~h}$ & 92 \\
- & $90{ }^{\circ} \mathrm{C}(\mathrm{mw})$ & $30 \mathrm{~min}$ & 43 \\
- & $120{ }^{\circ} \mathrm{C}(\mathrm{mw})$ & $30 \mathrm{~min}$ & 64 \\
- & $120{ }^{\circ} \mathrm{C}(\mathrm{mw})$ & $60 \mathrm{~min}$ & 76 \\
- & $150{ }^{\circ} \mathrm{C}(\mathrm{mw})$ & $30 \mathrm{~min}$ & 82 \\
- & $180{ }^{\circ} \mathrm{C}(\mathrm{mw})$ & $30 \mathrm{~min}$ & 91 \\
Pyridine & $110{ }^{\circ} \mathrm{C}(\mathrm{mw})$ & $10 \mathrm{~min}$ & 92
\end{tabular}

approximation of the conversion of about $65 \%$ for pyridinesulfonamide 6 and a conversion of $92 \%$ to methylsulfonamide 4 . In contrast to the previous approaches using Cr-MIL-101- $\mathrm{SO}_{3} \mathrm{H}$, the addition of pyridine as a catalyst and scavenger for the generated hydrochloric acid showed a significant improvement of conversion in both cases.

Due to the stability of methylsulfonyl chloride at higher temperatures, the reaction conditions for the synthesis of sulfonamide 4 were optimized by performing the reaction in a normal glass vessel as well as under microwave conditions.

In summary, we report a synthetic strategy for introducing the sulfonamide functionality into MOFs for the first time. Amino and sulfonic acid containing MOFs like CAU-1- $\mathrm{NH}_{2}$ and Cr-MIL-101- $\mathrm{SO}_{3} \mathrm{H}$ can be modified by using sulfonyl chlorides as reactive intermediates in two different routes. With the broad variation of substituents and the different orientations of the sulfonamide moiety to the framework, this method offers a promising tool for the postsynthetic modification of amino and sulfonic acid containing frameworks. Above all, the sulfonamide group is a powerful functionality with respect to catalysis and host-guest interactions. Their implementation into MOFs makes them promising materials for future developments.

Financial support of the Deutsche Forschungsgemeinschaft (SPP 1362) is gratefully acknowledged.

\section{Notes and references}

1 (a) O. M. Yaghi, M. O'Keeffe, N. W. Ockwig, H. K. Chae, M. Eddaoudi and J. Kim, Nature, 2003, 423, 705; (b) S. Kitagawa, R. Kitaura and S. Noro, Angew. Chem., Int. Ed., 2004, 43, 2334 (Angew. Chem., 2004, 116, 2388); (c) G. Férey, Chem. Soc. Rev., 2008, 37, 191; (d) D. Farusseng, Metal-Organic Frameworks, Wiley-VCH, Weinheim, 2011.

2 (a) H.-C. Zhou, J. R. Long and O. M. Yaghi, (ed.) Chem. Rev., 2012, 112, 673; (b) J. R. Long and O. M. Yaghi, (ed.) Chem. Soc. Rev., 2009, 38, 1201; (c) C. Wang, D. Liu and W. Lin, J. Am. Chem. Soc., 2013, 135, 13222; (d) S. H. Jhung, N. A. Khan and Z. Hasan, CrystEngComm, 2012, 14, 7099; (e) S. T. Meek, J. A. Greathouse and M. D. Allendorf, Adv. Mater., 2011, 23, 249; $(f)$ B. Van de Voorde, B. Bueken, J. Denayer and D. De Vos, Chem. Soc. Rev., 2014, DOI: 10.1039/ c4cs00006d; $(g)$ A. Dhakshinamoorthy and H. Garcia, Chem. Soc. Rev., 2014, DOI: 10.1039/c3cs60442j; (h) E. Coronado and G. Mínguez Espallargas, Chem. Soc. Rev., 2013, 42, 1525.

3 S. M. Cohen, Chem. Rev., 2012, 112, 970.

4 (a) S. Bauer, C. Serre, T. Devic, P. Horcajada, J. Marrot, G. Férey and N. Stock, Inorg. Chem., 2008, 47, 7568; (b) J. S. Costa, P. Gamez, C. A. Black, O. Roubeau, S. J. Teat and J. Reedijk, Eur. J. Inorg. Chem., 2008, 1551; (c) K. Koh, A. G. Wong-Foy and A. J. Matzger, Angew. Chem., Int. Ed., 2008, 47, 677 (Angew. Chem., 2008, 120, 689); (d) Z. Wang, K. K. Tanabe and S. M. Cohen, Inorg. Chem., 2009, 48, 296; (e) M. Eddaoudi, J. Kim, N. Rosi, D. Vodak, J. Wachter, M. O'Keeffe and O. M. Yaghi, Science, 2002, 295, 469; $(f)$ T. Ahnfeldt, N. Guillou, D. Gunzelmann, I. Margiolaki, T. Loiseau, G. Férey, J. Senker and N. Stock, Angew. Chem., Int. Ed., 2009, 48, 5163 (Angew. Chem., 2009, 121, 5265).

5 T. Ahnfeldt and N. Stock, CrystEngComm, 2012, 14, 505.

6 W. Morris, C. J. Doonan, H. Furukawa, R. Banerjee and O. M. Yaghi, J. Am. Chem. Soc., 2008, 130, 12626.

7 T. Gadzikwa, G. Lu, C. L. Stern, S. R. Wilson, J. T. Hupp and S. T. Nguyen, Chem. Commun., 2008, 5493.

8 Y. Goto, H. Sato, S. Shinkai and K. Sada, J. Am. Chem. Soc., 2008, 130, 14354.

9 (a) S. J. Garibay, Z. Wang, K. K. Tanabe and S. M. Cohen, Inorg. Chem., 2009, 48, 7341; (b) D. Britt, C. Lee, F. J. Uribe-Romo, H. Furukawa and O. M. Yaghi, Inorg. Chem., 2010, 49, 6387.

10 (a) M. J. Ingleson, J. P. Barrio, J.-B. Guilbaud, Y. Z. Khimyak and M. J. Rosseinsky, Chem. Commun., 2008, 2680; (b) C. J. Doonan, W. Morris, H. Furukawa and O. M. Yaghi, J. Am. Chem. Soc., 2009, 131, 9492.

11 (a) T. Ahnfeldt, D. Gunzelmann, T. Loiseau, D. Hirsemann, J. Senker, G. Férey and N. Stock, Inorg. Chem., 2009, 48, 3057; (b) M. Savonnet, D. Bazer-Bachi, N. Bats, J. Perez-Pellitero, E. Jeanneau, V. Lecocq, C. Pinel and D. Farrusseng, J. Am. Chem. Soc., 2010, 132, 4518.

12 (a) N. Reimer, B. Gil, B. Marszalek and N. Stock, CrystEngComm, 2012, 14, 4119; (b) M. I. H. Mohideen, B. Xiao, P. S. Wheatley, A. C. McKinlay, Y. Li, A. M. Z. Slawin, D. W. Aldous, N. F. Cessford, T. Düren, X. Zhao, R. Gill, K. M. Thomas, J. M. Griffin, S. E. Ashbrook and R. E. Morris, Nat. Chem., 2011, 3, 304.

13 G. L. Patrick, An Introduction to Medicinal Chemistry, Oxford University Press, 1995.

14 (a) T. Kano, R. Sakamoto, Y. Yamaguchi, K. Itoh and K. Maruoka, Chem. Commun., 2013, 49, 1118; (b) L. Zu, H. Xie, H. Li, J. Wang and W. Wang, Org. Lett., 2008, 10, 1211; (c) Z. Xu, R. Wang, J. Xu, C.-S. Da, W.-J. Yan and C. Chen, Angew. Chem., Int. Ed., 2003, 42, 5747 (Angew. Chem., 2003, 115, 5925).

15 C. S. Hunter, Angew. Chem., Int. Ed., 2004, 43, 5310 (Angew. Chem., 2004, 116, 5424).

16 G. Akiyama, R. Matsuda, H. Sato, M. Takata and S. Kitagawa, Adv. Mater., 2011, 23, 3294.

17 (a) S. Biswas, J. Zhang, Z. Li, Y.-Y. Liu, M. Grzywa, L. Sun, D. Volkmer and P. Van Der Voort, Dalton Trans., 2013, 42, 4730; (b) M. Lin Foo, S. Horike, T. Fukushima, Y. Hijikata, Y. Kubota, M. Takata and S. Kitagawa, Dalton Trans., 2012, 41, 13791; (c) Postsynthetic partial sulfatation: M. G. Goesten, J. Juan-Alcañiz, E. V. Ramos-Fernandez, K. B. S. S. Gupta, E. Stavitski, H. van Bekkum, J. Gascon and F. Kapteijn, J. Catal., 2011, 281, 177.

18 M. Kajino, A. Hasuoka and H. Nishida, US Pat., US 20070060623A1, 2007. 